\title{
El comercio justo en el marco de la contratación publica
}

\author{
Fair Trade in the Framework of Public Procurement
}

\author{
Carmen Agoués Mendizabal \\ Profesora Titular de Derecho Administrativo de la Universidad del País Vasco \\ carmen.agoues@ehu.eus \\ http://orcid.org/0000-0002-7582-5993
}

Sumario: I. Consideraciones Iniciales.-II. El Comercio Justo. 1. Definición. 2. Los principios de Comercio Justo para fomentar unas relaciones comerciales más justas.-III. La contratación pública y el Comercio Justo en el marco normativo europeo. 1. La incorporación del Comercio Justo en el marco de la Unión Europea. 2. Las Directivas 2004/17/CE y 2004/18/CE sobre contratación pública. 3. La Directiva 2014/24/UE sobre contratación pública y el Comercio Justo. 4. Las etiquetas de Comercio Justo.-IV. La incorporación de cláusulas de Comercio Justo en en Ley 9/2017, de 8 de noviembre, de Contratos del Sector Público. 1. Introducción. 2. Fase de preparación de los contratos 3. Los criterios de adjudicación de los contratos. 4. Condiciones especiales de ejecución de los contratos. $-\mathrm{V}$. Conclusiones.

Resumen: El presente estudio analiza la contratación del sector público como instrumento decisivo para promover unas relaciones de comercio más justas y contribuir así al respeto de los derechos humanos. La Ley de Contratos del Sector Público de 2017 permite incluir los criterios de Comercio Justo en el pliego de prescripciones técnicas particulares, en los criterios de adjudicación del contrato y/o en las condiciones de ejecución del contrato. Ahora bien, el alcance de la contratación pública, como instrumento para la consecución de un comercio que respete los principios vinculados al Comercio Justo, dependerá del compromiso adquirido por cada ente contratante en su política de contratación de bienes y servicios.

Palabras clave: derechos humanos, contratación pública, Comercio Justo, fases en el procedimiento de contratación pública, etiquetas.

Abstract: The present study analyzes public procurement as a key tool to promote fairer trade relations and contribute to respect for human rights. Spanish Public Procurement Law of 2017 allows the Fair Trade criteria to be included in the specifications of particular technical requirements, in the contract award criteria and / or in contract performance conditions. However, the scope of public 
procurement, as an instrument to achieve a trade that respects the principles related to Fair Trade, will depend on the commitment acquired by each contracting entity in its policy of procurement of goods and services.

Keywords: Human rights, public procurement, Fair Trade, different stages in a public procurement procedure, labels.

\section{Consideraciones Iniciales}

Las grandes compañías externalizan algunas actividades empresariales en países que proporcionan mano de obra más barata y cuya normativa laboral y ambiental resulta menos restrictiva. Los productores de países en vías de desarrollo, que no disponen de mercados alternativos para comercializar sus productos, se ven forzados a vender sus productos por debajo del coste de producción. En esta coyuntura, la grandes firmas adquieren los productos al margen del coste social y ambiental de sus decisiones. Además, algunos sectores de estas cadenas de producción resultan particularmente vulnerables a las prácticas comerciales desleales, y resultan víctimas de prácticas como pagos atrasados, modificaciones unilaterales o retroactivas de los acuerdos de suministro o cancelación de pedidos ${ }^{1}$.

Las cadenas de producción de algunas compañías se ven sometidas, en ocasiones, a conductas que constituyen una clara vulneración de los derechos humanos ${ }^{2}$. No obstante, en muchos casos, estas compañías resultan adjudicatarias de contratos del sector público en distintos estados miembros de la Unión Europea.

Este trabajo pretende contribuir a dar un paso más en ese objetivo de conseguir que en el marco de las cadenas de suministro globales se respeten

1 Vid. la Directiva (UE) 2019/633 del Parlamento Europeo y del Consejo, de 17 de abril de 2019 relativa a las prácticas comerciales desleales en las relaciones entre empresas en la cadena de suministro agrícola y alimentario (DOUE 25/04/2019). En 2016, la Unión Europea importó 100.000 millones de euros de alimentos, lo que significa que cientos de miles de agricultores y productores de todo el mundo dependen de sus relaciones comerciales con el mercado de la UE. Vid al respecto: http://comerciojusto.org/una-nueva-directiva-europeahara-frente-a-las-practicas-comerciales-desleales-en-el-sector-agricola/, acceso el 8 de octubre de 2019.

2 En 2014, Amnistía Internacional publicó el informe «Injustice Incorporated: Corporate abuses and the human right to remedy (Injustice Incorporated)», que ponía de manifiesto los obstáculos para la obtención de remedio en casos de violaciones de derechos humanos cometidas por empresas. Acceso, 9 de octubre de 2019, https://www.amnesty.org/en/documents/ pol30/7037/2017/en/. 
los derechos humanos y se prohíban las prácticas comerciales desleales, especialmente, de los productores que son el eslabón más débil y que se ubican generalmente en los países menos desarrollados. Los Derechos Humanos son uno de los principios clave de la norma ISO 20400, estándar sobre compra sostenible ${ }^{3}$, que define la compra sostenible como aquélla que tiene los impactos más positivos posibles desde el punto de vista medioambiental, social y económico durante todo el ciclo de vida ${ }^{4}$.

El presente estudio pretende poner de relieve que el sector público puede contribuir de manera relevante a fomentar el comercio ético, a que las empresas comprometidas con los derechos humanos se beneficien de una mejor valoración en la adjudicación de contratos públicos, y contribuir, de manera indirecta, a su mejor reputación ante los inversores y los consumidores.

En el marco de la contratación del sector público, las cláusulas sociales vinculadas al Comercio Justo pueden constituir un instrumento decisivo para contribuir a mejorar la situación de pequeños productores que se encuentran en la posición más endeble en la negociación comercial. Las Administraciones públicas y los entes del sector público constituyen importantes activos para, a través de la contratación pública, favorecer un comercio más equitativo para los pequeños productores de los países en desarrollo.

Según el Observatorio de la Contratación Pública, la contratación pública representa alrededor de $20 \%$ del PIB de España ${ }^{5}$. Como veremos en los siguientes apartados, los órganos de contratación del sector público pueden hacer valer cláusulas de Comercio Justo en las distintas fases de la contratación pública; de este modo, las autoridades públicas pueden, por ejemplo, priorizar al licitador que incluya en su oferta productos y servicios con criterios de Comercio Justo.

La orientación estratégica de la contratación pública hacia la igualdad de oportunidades y la justicia social encuentra también su fundamento jurídico en los principios del Derecho de la UE. El Parlamento Europeo en su Resolución 2005/2245, sobre Comercio Justo y Desarrollo ${ }^{6}$, considera que el Comercio

${ }^{3}$ Publicada el 20 de abril de 2017. Acceso 9 de octubre de 2019:

https://www.iso.org/obp/ui\#iso:std:iso:20400:ed-1:v1:es.

${ }^{4}$ La norma ISO 20400 describe en detalle todos los impactos de sostenibilidad y consideraciones que se deben incorporar en los distintos aspectos de las actividades de adquisición. Es una actualización de BS 8903, ya que tiene en cuenta todos los nuevos conceptos como pueden ser el ciclo de vida, la complicidad y el coste global. En su elaboración han participado más de 40 naciones de Europa, Africa, América Central y América del Sur, así como EEUU, Canadá, Australia, Japón, China.

5 Acceso, el 4 de octubre de 2019, http://www.obcp.es/.

6 Resolución del Parlamento Europeo sobre comercio justo y desarrollo (2005/2245(INI). Acceso, el 9 de octubre de 2019, http://www.europarl.europa.eu/sides/getDoc.do?pubRef=-//EP//TEXT+TA+P6-TA-2006-0320+0+DOC+XML+V0//ES 
Justo y otras iniciativas comerciales sujetas a controles independientes, constituyen instrumentos importantes «para la reducción de la pobreza y el desarrollo sostenible, garantizando un acceso estable y sostenible al mercado europeo y aumentando la sensibilización de los consumidores y considerándolo como instrumento válido para alcanzar los Objetivos de Desarrollo del Milenio».

La cuarta generación de Directivas de contratación pública ha asumido una visión estratégica de la compra pública ${ }^{7}$ con el objeto de posibilitar y facilitar la incorporación de aspectos sociales en los procesos de licitación de contratos públicos, y coadyuvar a alcanzar los objetivos de la Estrategia Europa 2020. Las Directivas 2014/23/UE, 2014/24/UE y 2014/25/UE, han promovido la denominada «contratación pública estratégica», para favorecer la consecución de objetivos propios de políticas públicas sociales y laborales, medioambientales, de apoyo a la PYMEs, la innovación y el desarrollo o la defensa de la competencia.

Desde esta perspectiva, el presente estudio pretende abordar las posibilidades que ofrece la contratación pública como medio de desarrollar objetivos sociales, y en concreto, el Comercio Justo. Con este objetivo, se aborda, en primer lugar, el propio concepto de «Comercio Justo» y sus principios; a continuación se analiza el marco europeo de contratación pública, para pasar a examinar los mecanismos de contratación pública previstos en el ordenamiento jurídico español que permiten incidir y promover una compra más sostenible y solidaria. En concreto, se expondrán las posibilidades que tienen los órganos de contratación para utilizar criterios de Comercio Justo en sus licitaciones públicas en las distintas fases de la contratación pública; concretamente en la preparación y definición del contrato, a la hora de establecer los criterios de adjudicación del contrato y al establecer las condiciones especiales de ejecución del contrato.

\section{El Comercio Justo}

\section{Definición}

Es preciso adelantar que no existe un concepto normativo de Comercio Justo. Tanto la Comisión Europea como el Parlamento Europeo han

${ }^{7}$ Conformada por la Directivas 2014/23/UE, del Parlamento Europeo y del Consejo, relativa a la adjudicación del contrato de concesión; la Directiva 2014/24/UE, del Parlamento Europeo y del Consejo, sobre contratación pública y por la que se deroga la Directiva 2004/18/CE; y 2014/25/UE, del Parlamento Europeo y del Consejo, relativa a la contratación por entidades que operan en los sectores del agua, la energía, los transportes y los servicios postales, y por la que se deroga la Directiva 2004/17/CE. 
adoptado la definición formulada por FINE, que constituye una plataforma integrada por los principales referentes de Comercio Justo ${ }^{8}$ y define el Comercio Justo como:

«Una relación de intercambio comercial basada en el diálogo, la transparencia y el respeto, que busca una mayor equidad en el comercio internacional. Contribuye al desarrollo sostenible ofreciendo mejores condiciones comerciales y asegurando los derechos de los pequeños productores y trabajadores marginados, especialmente del Sur. Las organizaciones de Comercio Justo, apoyadas por los consumidores, están activamente comprometidas en apoyar a los productores, sensibilizar y desarrollar campañas para conseguir cambios en las reglas y prácticas del comercio internacional convencional».

Tal y como sostiene MEDINA ARNAIZ, los primeros pasos en iniciativas de Comercio Justo datan de finales de los años cuarenta en Estados Unidos ${ }^{9}$. En 1964, en el seno de la primera Conferencia de las Naciones Unidas sobre Comercio y Desarrollo (UNCTAD), bajo el lema «Comercio, no ayuda», los países en desarrollo exigieron que se abrieran las fronteras a sus productos agrícolas y reivindicaron un nuevo orden económico internacional con relaciones comerciales más justas que permitieran su desarrollo económico. En la actualidad, muchas ciudades están comprometidas con la promoción del Comercio Justo en sus muni$\operatorname{cipios}^{10}$.

El Comercio Justo persigue proporcionar oportunidades de desarrollo a pequeños productores y trabajadores de países en vías de desarrollo, y orientar el sistema de comercio internacional y de las empresas privadas

${ }^{8}$ La definición fue acordada en el 2001 por Fairtrade Labelling Organizations International (FLO), International Federation for Alternative Trade (IFAT), Network of World Shops (NEWS), y European Fair Trade Asociation (EFTA). IFAT ha sido renombrada como World Fair Trade Organization e incluye a la ex organización NEWS.

9 Teresa Medina Arnaiz, opinión emitida para el Observatorio de Contratación pública con fecha 16/03/2015,http://www.obcp.es/index.php/mod.opiniones/mem.detalle/id.190/relcategoria.121/relmenu.3/chk.d1be71b14d176574721ed2e36b274381.

Explica la autora que a finales de los años cuarenta en Estados Unidos, las organizaciones Ten Thousand Villages y SERRV establecieron vínculos directos con productores artesanales de países del Sur para comercializar sus productos. También en Europa, a finales de los cincuenta, OXFAM UK empezó a comercializar artesanía fabricada por refugiados chinos, en sus tiendas del Reino Unido. Asimismo, en los Países Bajos, jóvenes católicos neerlandeses crearon una asociación para importar productos de los países en desarrollo bajo la modalidad de «tiendas solidarias».

102000 ciudades de Comercio Justo en más de 30 países. Vid. la página web, con acceso 8 de octubre 2019, http://www.fairtradetowns.org/. 
hacia un comportamiento justo que favorezca el desarrollo sostenible ${ }^{11}$. En este marco, el Comercio Justo promueve un nuevo paradigma para los procesos de contratación pública, que obliga a ir más allá de los criterios económicos en la adjudicación de los contratos públicos.

Los agentes intervinientes en el Comercio Justo son varios: los grupos productores, que normalmente están organizados en cooperativas o asociaciones $^{12}$; las empresas que importan productos de Comercio Justo que compran directamente a los grupos productores y distribuyen las mercancías; las tiendas de Comercio Justo, que desarrollan una labor comercial; y los consumidores.

Las organizaciones de Comercio Justo tienen por objeto comercializar productos bajo estos criterios y sensibilizar a los consumidores y desarrollar campañas para conseguir cambios en las reglas y prácticas del comercio internacional convencional.

Las normas sobre el Comercio Justo se establecen de acuerdo con lo exigido por la Alianza Internacional para la Certificación y el Etiquetado Social y Medioambiental (International Social and Environment Accreditations and Labelling Alliance - ISEAL). Esta Alianza es una colaboración formal de organizaciones internacionales de normalización y de evaluación de la conformidad centrada en asuntos sociales y ambientales.

Existen dos organismos internacionales de normalización del Comercio Justo que certifican a las organizaciones del Comercio Justo en todo el mundo, siguiendo los principios de ISEAL: la Organización Internacional de Etiquetado de Comercio Justo (Fairtrade Labelling Organizations $F L O$ ) y la Organización Mundial de Comercio Justo (World Fair Trade Organization - WFTO), que es miembro asociado de ISEAL.

\section{Los principios de Comercio Justo para fomentar unas relaciones comerciales más justas}

La Organización Mundial de Comercio Justo (WFTO) ${ }^{13}$ ha establecido 10 principios que deben ser cumplidos por las organizaciones que trabajan en Comercio Justo. Los diez criterios incluyen: la creación de oportunidades para productores con desventajas económicas para favore-

11 Vid. en este sentido, el Informe sobre Comercio justo y desarrollo (2005/2245 (INI), Comisión de Desarrollo, del Parlamento Europeo.

${ }^{12}$ En su mayoría son grupos de Asia, África, Oceanía y América Central y del Sur.

13 Es la entidad de mayor representatividad del Comercio Justo; constituye una red mundial integrada por más de 300 organizaciones de más de 60 países que acredita a Organizaciones de Comercio Justo que cumplan los 10 criterios. 
cer su desarrollo comercial; la transparencia y gestión democrática, que exige involucrar a los productores en los procesos de toma de decisiones; una relación comercial equitativa a largo plazo con los productores ${ }^{14}$; un precio justo $^{15}$ a los productores que cubra los costes de una producción y un modo de vida digno; asegurar la ausencia de trabajo infantil y trabajo forzoso ${ }^{16}$; no discriminación, igualdad de género y el empoderamiento económico de la mujer y la libertad de asociación; protección de los derechos humanos y de los trabajadores ${ }^{17}$; desarrollar actividades específicas para ayudar a los productores a mejorar sus habilidades de gestión, capacidades de producción y el acceso a los mercados locales, regionales o internacionales de Comercio Justo; y el cuidado del medio ambiente a través del uso de materias primas de fuentes gestionadas en forma sostenible y el uso de tecnologías de producción que buscan reducir el consumo de energía.

Estos principios constituyen una «forma de comercio» para la consecución de unas relaciones comerciales más justas. Los principios mencionados pretenden vincular la competitividad económica con la justicia social y el respeto al medio ambiente.

La Agenda 2030 para el Desarrollo Sostenible ${ }^{18}$, adoptada por la Asamblea General de las Naciones Unidas en 2015, plantea distintos objetivos y el número 17 (Fortalecer los medios de ejecución y revitalizar la Alianza Mundial para el Desarrollo Sostenible) en su punto 12 se marca como Ob-

${ }^{14}$ Los compradores de Comercio Justo deben asegurar que los pedidos sean pagados al momento de recibir los productos y de acuerdo a los criterios acordados por ambas partes. Los compradores deben consultar con los proveedores antes de cancelar o rechazar un pedido. Cuando los pedidos son cancelados por causas ajenas a los productores o proveedores, se debe garantizar una compensación adecuada por el trabajo ya hecho.

${ }^{15}$ Un precio justo es aquel que ha sido establecido de mutuo acuerdo por todos a través del diálogo y la participación, que proporciona un pago justo a los productores y también puede ser sostenido por el mercado. También se debe garantizar un pago justo, es decir, la provisión de una remuneración socialmente aceptable (en el contexto local), considerado justo por los mismos productores y que tiene en cuenta el principio de pago igual por trabajo igual tanto para mujeres como para los hombres.

${ }^{16}$ Las Organizaciones que compran productos de Comercio Justo de los grupos de productores, sea directamente o a través de intermediarios, se deben asegurar de que no se utilice el trabajo forzoso en la producción y que el productor cumpla con la Convención de las Naciones Unidas sobre los Derechos del Niño y las leyes nacionales/locales sobre el empleo de niños y niñas.

17 Se ha de cumplir, como mínimo, con las leyes nacionales y regionales y los convenios de la Organización Internacional del Trabajo - OIT, sobre la salud y la seguridad. Las organizaciones de Comercio Justo se han de informar sobre las condiciones de salud y seguridad de los grupos productores que les venden los productos.

18 Aprobada mediante Resolución 70/1 de la Asamblea General de Naciones Unidas (AGNU) de 25 de septiembre de 2015. 
jetivo «Lograr la consecución oportuna del acceso a los mercados, libre de derechos y de contingentes, de manera duradera para todos los países menos adelantados (...), entre otras cosas velando por que las normas de origen preferenciales aplicables a las importaciones de los países menos adelantados sean transparentes y sencillas y contribuyan a facilitar el acceso a los mercados».

Por su parte, el Parlamento Europeo, siguiendo los principios referidos, en el art. 2 de la Resolución n. ${ }^{2} 245 / 2005$, establece que el Comercio Justo debe cumplir una serie de criterios definidos por el movimiento en favor del Comercio Justo en Europa:

a) un precio justo al productor, que garantice unos ingresos justos y que permita cubrir unos costes sostenibles de producción y los costes de subsistencia; este precio debe igualar, por lo menos, al precio y la prima mínimos definidos por las asociaciones internacionales de comercio justo

b) parte del pago se debe efectuar por adelantado, si el productor así lo solicita

c) una relación estable y a largo plazo con los productores, así como la intervención de éstos en el establecimiento de normas de comercio justo

d) transparencia y rastreabilidad en toda la cadena de abastecimiento, a fin de garantizar una información adecuada al consumidor

e) unas condiciones de producción que respeten los ocho convenios fundamentales de la Organización Internacional del Trabajo (OIT)

f) el respeto del medio ambiente, la protección de los derechos humanos, en particular de los derechos de las mujeres y los niños, así como el respeto de los métodos de producción tradicionales que favorezcan el desarrollo económico y social

g) programas de desarrollo de capacidades y capacitación para los productores, en especial para los pequeños productores marginales de los países en desarrollo, para sus organizaciones y para sus respectivas comunidades, a fin de garantizar la sostenibilidad del comercio justo

h) el respaldo a la producción y la entrada al mercado de las organizaciones de productores

i) actividades de sensibilización sobre la producción y las relaciones comerciales en el marco del comercio justo, su misión y sus objetivos, y sobre la injusticia reinante en las normas del comercio internacional

j) el seguimiento y la verificación del cumplimiento de estos criterios, en cuyo marco debe corresponder un importante papel a las orga- 
nizaciones del hemisferio sur, con miras a una reducción de costes y una mayor participación de las mismas en el proceso de certificación

k) evaluaciones de impacto periódicas sobre las actividades relacionadas con el comercio justo

Por su parte, el Parlamento Europeo, mediante una Resolución de junio de 2016 sobre la responsabilidad de las empresas por violaciones graves de los derechos humanos en terceros países, se ha pronunciado a favor de la adopción de los Principios Rectores de las Naciones Unidas en relación con los principios rectores sobre las empresas y los derechos humanos ${ }^{19}$, pide a los Estados miembros «que prioricen como acción inmediata el establecimiento de la diligencia debida obligatoria en materia de derechos humanos en el caso de las empresas que suministran bienes o servicios mediante contratos públicos».

Es preciso, también, hacer una breve referencia al Acuerdo sobre Contratación Pública (ACP) que entró en vigor en 201420; se trata de un acuerdo plurilateral negociado en el marco de la $\mathrm{OMC}^{21}$, que tiene por objeto garantizar condiciones de competencia abiertas, equitativas y transparentes en la esfera de la contratación pública. El texto del Acuerdo establece principios generales y prescripciones de procedimiento detalladas que las partes en el ACP están obligadas a aplicar en las actividades de contratación abarcadas $\mathrm{y}$, entre ellas, cabe destacar las disposiciones sobre trato especial y diferenciado para los países en desarrollo en las que se prevén medidas de transición destinadas a apoyar las prioridades de desarrollo de esos países ${ }^{22}$; la Di-

19 Resolución 17/4, de 16 de junio de 2011 que recoge los Principios Rectores sobre las empresas y los derechos humanos.

${ }^{20}$ El Acuerdo sobre Contratación Pública (ACP) cuenta actualmente con 20 Partes, que abarcan a 48 Miembros de la OMC. Se cuenta como una sola Parte a la Unión Europea y sus 28 Estados miembros, todos los cuales se han adherido al Acuerdo. El ACP revisado, entró en vigor el 6 de abril de 2014. consultar en: https://www.wto.org/spanish/tratop_s/gproc_s/gp_ gpa_s.htm. Acceso 11 de octubre de 2019.

21 Vid sobre el ACP: Rodriguez Arana, Jaime Jaime Jinesta Lobo, José Antonio Moreno Molina, Karlos Navarro Medal y Ernesto Jinesa Lobo., Derecho Internacional de las Contrataciones Públicas, Konrad Adenauer Stiftung, Costa Rica: Editorial Guayacán, 2011), 57-64. http://www.kas.de/wf/doc/kas_29075-1522-4-30.pdf?111012200416.

22 Artículo V: Trato especial y diferenciado para los países en desarrollo

En la aplicación y administración del presente Acuerdo, y de conformidad con las disposiciones enunciadas en este artículo, las Partes tendrán debidamente en cuenta las necesidades de desarrollo, financieras y comerciales de los países en desarrollo, en particular de los países menos adelantados, considerando su necesidad de: a) salvaguardar la situación de su balanza de pagos y garantizar un nivel de reservas suficiente para la realización de programas de desarrollo económico; b) promover la creación o el desarrollo de ramas de producción nacionales, incluido el desarrollo de las pequeñas industrias y la artesanía en las zonas rurales o atrasadas, así como el desarrollo de otros sectores de la economía; c) apoyar a los estable- 
rectiva 2014/24/UE se hace eco del ACP al hacer referencia a la necesidad de conciliar los objetivos del $\mathrm{ACP}^{23}$.

Finalmente, resulta ineludible referirse a la reciente Directiva (UE) 2019/633 del Parlamento Europeo y del Consejo, de 17 de abril de 2019, relativa a las prácticas comerciales desleales en las relaciones entre empresas en la cadena de suministro agrícola y alimentario ${ }^{24}$, que con el objetivo de luchar contra las prácticas desleales, establece una lista mínima de prácticas comerciales desleales prohibidas en las relaciones entre compradores y proveedores en la cadena de suministro agrícola y alimentario e impone unas normas mínimas en relación con el control del cumplimiento de esas prohibiciones, así como disposiciones para la coordinación entre las autoridades encargadas de ese control del cumplimiento. La Directiva se aplica a las ventas entre un proveedor y un comprador cuando uno de los dos, o ambos, estén establecidos en la Unión. Además, debe aplicarse a todas las autoridades públicas que actúen como compradoras. Cabe destacar entre las prácticas prohibidas: la morosidad en el pago de productos agrícolas y alimentarios, la cancelación con escasa antelación de los pedidos de productos perecederos; las represalias del comprador contra un proveedor que ejerce sus derechos, o la amenaza de tomar tales represalias.

\section{La contratación pública y el Comercio Justo en el marco normativo europeo}

\section{La incorporación del Comercio Justo en el marco de la Unión Europea}

El art. 3.5 del Tratado de la Unión Europea ${ }^{25}$, establece que la Unión Europea en sus relaciones con el resto del mundo, contribuirá, entre otros

cimientos industriales que dependan totalmente o en medida considerable de la contratación pública; d) fomentar su desarrollo económico mediante acuerdos regionales o generales entre países en desarrollo, presentados a la Conferencia Ministerial de la Organización Mundial del Comercio (en adelante «OMC») y no desaprobados por ella.

2.De conformidad con las disposiciones del presente Acuerdo, en la preparación y aplicación de las leyes, reglamentos y procedimientos relativos a la contratación pública, cada Parte facilitará el aumento de las importaciones procedentes de los países en desarrollo, teniendo presentes los problemas especiales de los países menos adelantados y de aquellos países que se hallan en niveles bajos de desarrollo económico.

${ }^{23} \mathrm{Vid}$. los considerandos 17, 18, 80, 98 y 134, así como los arts. 6 y 25 de la Directiva 2014/24/UE.

24 «DOUE» núm. 111, de 25 de abril de 2019, páginas 59 a 72.

${ }_{25}$ Publicado en DOUE núm. 340 de 10 de noviembre de 1997 y $B O E$ de 13 de enero de 1994. 
aspectos al comercio libre y justo, la erradicación de la pobreza y la protección de los derechos humanos, especialmente los derechos del niño.

Atendiendo a dichos objetivos, la competencia exclusiva de la UE sobre política comercial comunitaria (art. 207 TFUE) ha de ponerse en relación con el art. 208 del TFUE ${ }^{26}$ que dispone como objetivo principal de la política de la Unión, la reducción y la erradicación de la pobreza. Asimismo, establece que la Unión tendrá en cuenta los objetivos de la cooperación para el desarrollo al aplicar las políticas que puedan afectar a los países en desarrollo.

Las dos primeras generaciones de Directivas comunitarias en el ámbito de la contratación pública ${ }^{27}$ venían marcadas por el objetivo de remover los obstáculos para la consecución de un Mercado Común Único, sin atender a aspectos sociales; han sido los documentos sowt law, aprobados en su mayoría por la Comisión, y la propia jurisprudencia del TJUE, los principales actores en la introducción de aspectos sociales y ambientales en la contratación pública ${ }^{28}$.

Ya en 1996 se publicó por la Comisión el Libro Verde, de 27 de noviembre de 1996, "La contratación Europea: Reflexiones para el

${ }^{26}$ Publicado en DOUE C 83/49, de 30 de marzo de 2010.

${ }^{27}$ La Directiva 70/32/CEE de la Comisión, de 17 de diciembre de 1969, sobre suministros de productos del Estado, sus entes territoriales y personas jurídicas de Derecho público; la Directiva 71/304/CEE, de 26 de julio de 1971, relativa a la supresión de restricciones a la libre prestación de servicios en el sector de contratos públicos de obras y a la adjudicación de contratos públicos de obras por medio de agencias o sucursales; Directiva 71/305/CEE del Consejo, sobre coordinación de los procedimientos de adjudicación de los contratos públicos de obras: la Directiva 77/62/CEE del Consejo, de 21 de diciembre de 1976, de coordinación de los procedimientos de adjudicación de contratos públicos de suministros; la Directiva 88/295/CEE del Consejo, de 22 de marzo de 1988, por la que se modifica la Directiva 77/62/CEE de coordinación de los procedimientos de adjudicación de contratos públicos de suministro y por la que se derogan determinadas disposiciones de la Directiva 80/767/CEE; la Directiva 89/440/CEE del Consejo, de 18 de julio de 1989, que modifica la Directiva 71/305/CEE sobre coordinación de los procedimientos de celebración de los contratos públicos de obras; la Directiva 92/50/CEE, de 18 de junio de 1992, sobre los contratos de servicios, la Directiva 93/36/CEE, de 14 de junio de 1993, sobre los contratos de suministros, y la Directiva 93/37/CEE, de 14 de junio de 1993, sobre los contratos de obras, modificadas todas ellas posteriormente por la Directiva 97/52/CE, del Parlamento y el Consejo de 13 de octubre de 1997. A ellas habría que unir la Directiva 93/38/CEE, del Consejo, de 14 de junio de 1993, sobre coordinación de los procedimientos de adjudicación de contratos en los sectores del agua, la energía, los transportes y de las telecomunicaciones.

28 Vid. Manuel Gomez Ruiz, Aspectos sociales y medioambientales de la contratación pública, (Universidad de Cádiz, 2015), 39-68.

https://rodin.uca.es/xmlui/bitstream/handle/10498/18516/ASPECTOS\%20SOCIALES\%20Y\%20MEDIOAMBIENTALES\%20EN\%20LA\%20CONTRATACI\%C3\%93N\%20 P\%C3\%9ABLICA..pdf?sequence $=1 \&$ isAllowed $=\mathrm{y}$ 
futuro» ${ }^{29}$, en donde se sostenía que la normativa sobre contratación pública podía contribuir a cumplir los objetivos de la política social y del medioambiente. Se estimaba que las Directivas vigentes en aquel momento permitían excluir de la licitación a los empresarios que hubieran cometido una falta grave relacionada con la infracción de una legislación encaminada a fomentar objetivos sociales; asimismo, se consideraba que no cabía incluir cláusulas sociales como criterios de adjudicación de los contratos y que cabía la inclusión de cláusulas sociales como meros criterios de desempate entre ofertas equivalentes o como condiciones de ejecución contractual a realizar por la empresa adjudica$\operatorname{taria}^{30}$.

El 17 de septiembre de 2002, el Tribunal de Justicia de la Comunidad Europea dictó la Sentencia «Concordia Bus Finland Oy Ab contra Helsingin kaupunki y otros $^{31}$ y entendió que los criterios de adjudicación adoptados por el órgano contratante no tienen que ser necesariamente de naturaleza económica, y refiriéndose a los requisitos medioambientales, sostuvo que «deben estar relacionados con el objeto del contrato».

La STJCE, de 4 de diciembre de 2003, EVN AG ${ }^{32}$, tras recoger la doctrina fijada en Beentjes y en Concordia Bus sostuvo que para que una cláusula de contenido social o ambiental sea válida como criterio de adjudicación, debe estar relacionada con el objeto del contrato, no puede otorgar a la entidad adjudicadora una libertad ilimitada de elección, debe cumplir con el principio de transparencia - anunciándose expresamente en el pliego de cláusulas administrativas o en el anuncio de licitación-, y debe respetar todos los principios fundamentales del Derecho comunitario, especialmente el de no discriminación ${ }^{33}$.

En esta coyuntura, instituciones europeas como el Parlamento Europeo o el Comité de las Regiones de la UE, entendieron el Comercio Justo como una forma de mejorar la gestión pública, e instaron a todos los Estados miembros a poner en marcha acciones que garantizasen, de forma sistemática, iniciativas de compra pública ética. Aludiré, a continuación, a algu-

${ }^{29}$ COM (96) 583 final, de 27 de noviembre de 1996.

30 Vid. José Antonio Moreno Molina y Franciso Pleite Guadamillas, Nuevo régimen de la contratación administrativa (adaptada al nuevo reglamento de contratos y a la Ley de Concesión de Obras Públicas), Madrid: La Ley, 2003, pág. 381.

31 C-513/99.

32 Asunto C-448/01. EVN y Wienstrom GmbH contra República de Austria.

${ }^{33}$ El TJUE sostuvo que la normativa comunitaria en materia de contratación pública no se opone a que una entidad adjudicadora establezca, para la determinación de la oferta económicamente más ventajosa a efectos de la adjudicación de un contrato de suministro de electricidad, un criterio consistente en exigir el suministro de electricidad generada a partir de fuentes de energía renovables, al que se atribuye un coeficiente de ponderación del $45 \%$. 
nos documentos que, junto a la jurisprudencia del TJUE, han contribuido a poner de relieve la importancia de insertar cláusulas de Comercio Justo en la contratación pública.

Así, la «Resolución sobre el consumo de café como actividad de apoyo a los pequeños productores de café en el Tercer Mundo y la introducción de este café en el seno de las instituciones comunitarias» adoptada por el Parlamento Europeo en 199134; o el Dictamen del Comité Económico y Social sobre el «Movimiento en favor de una marca de Fair Trade europea ${ }^{35}$ de 1996 , recomendaba crear una línea presupuestaria propia para promover la actividad de las organizaciones de certificación.

También en 1999 la Comunicación de la Comisión al Consejo relativa al «Comercio Justo» ${ }^{36}$, reconocía que con el Comercio Justo los productores de los países en desarrollo pueden obtener mayores ingresos por sus productos y tienen más posibilidades de encontrar nuevos mercados, hacía un llamamiento a favor de una etiqueta única e invocaba la necesidad de una verificación y un control independiente ${ }^{37}$.

Posteriormente, en el Informe sobre «Comercio justo y el desarrollo» de 2006 ${ }^{38}$, el Parlamento Europeo pidió la incorporación del concepto de «Comercio Justo» en todas las políticas de la UE, destacó el riesgo de aprovechamiento indebido por parte de las empresas que acceden al mercado del Comercio Justo sin cumplir los criterios de certificación. Asimismo, pidió a las entidades públicas territoriales que, en sus licitaciones, prestaran una atención especial a los productos del Comercio Justo; y subrayó que todas las instituciones de la UE deberían usar productos de Comercio Justo en sus servicios internos ${ }^{39}$.

La Comisión Europea, por su parte, en la Comunicación del 5 de mayo de 2009, Contribución al desarrollo sostenible: el papel del comercio justo y de los sistemas no gubernamentales de garantía de la sostenibilidad comercial ${ }^{40}$ señaló que, según las normas europeas de contratación pública, los órganos de contratación que desean comprar mercancías de Comercio Justo no pueden exigir etiquetas específicas, porque, de ese

\footnotetext{
34 Parlamento Europeo, 1991, p.34.

35 CES 538/96/24.4.96.

36 COM (1999)619 final.

37 Así, se ha introducido con éxito el «Sello de Certificación del comercio justo FAIR-
} TRADE».

38 Informe del Parlamento Europeo sobre comercio justo y desarrollo (2005/2245(INI).

39 En junio de 2006 el Consejo Europeo adoptó su estrategia revisada para un desarrollo sostenible y animó a los Estados miembros a promover los productos sostenibles, incluido el Comercio Justo. Acceso 11 de octubre de 2019, http://register.consilium.europa.eu/pdf/es/06/ st10/st10117.es06.pdf, página 13 .

40 COM(2009) 215 final. 
modo, podría limitarse el acceso a la contratación de productos que no están certificados como tales pero que cumplen normas similares de comercio sostenible. La Comisión entendió que las cláusulas de Comercio Justo pueden venir definidas en las especificaciones técnicas de las mercancías, deben ir unidas al objeto del contrato y cumplir las demás normas pertinentes de contratación pública de la UE. La Comisión señala que lo más relevante son los subcriterios que constituyen la base de las etiquetas, por ejemplo, la etiqueta «Fairtrade» y que cabe utilizar solo los que sean pertinentes al objeto de su compra ${ }^{41}$. Desde esa perspectiva, se debe permitir siempre a los licitadores demostrar el cumplimiento de estos criterios utilizando etiquetas de Comercio Justo u otros sistemas de etiquetado con los que se pretende informar a los consumidores sobre la sostenibilidad de la elaboración del producto ${ }^{42}$. Asimismo admite que los criterios ambientales y sociales también pueden incorporarse en las cláusulas de ejecución, siempre que estos criterios estén ligados a la ejecución del contrato en cuestión.

En su Dictamen de 2010, en relación a la referida Comunicación, el Comité de las Regiones ${ }^{43}$ sugiere la elaboración de una «Estrategia europea del comercio justo para los entes locales y regionales», que incorpore distintas medidas: sólo propongan café y té procedentes del Comercio Justo en sus reuniones, oficinas y comedores; los consejos municipales apoyen campañas en tal sentido; la labor de las «tiendas del mundo» se beneficie del reconocimiento de los municipios; las ciudades se esfuercen en el mayor número posible por verse recompensadas por el título de «Ciudades del Comercio Justo».

Finalmente, en la Comunicación «Comercio, crecimiento y desarrollo: Una política de comercio e inversión a medida para los países en desarrollo» (2012) ${ }^{44}$, la Comisión Europea invitó a los Estados miembros a fomentar el Comercio Justo y ético y a facilitar las opciones de compra de Comercio Justo y ético por parte de las autoridades públicas en Europa, en el contexto de la revisión de las directivas de contratación pública.

${ }^{41}$ Según la Comunicación de 2009, Europa es el hogar del Comercio Justo: entre el 60 $\%$ y el $70 \%$ de las ventas mundiales se produce en Europa, con grandes variaciones entre el mercado que está creciendo más rápidamente, Suecia, y los Estados miembros de más reciente incorporación, donde el concepto es aún relativamente nuevo.

${ }^{42}$ En el anexo I de la Comunicación figuran algunos términos y organizaciones.

43 2010/C 175/03, publicado en el DOUE C175, de 1 de julio de 2010. Se pone de relieve que los consumidores de la Unión Europea compran cada año productos que tienen el certificado de Comercio Justo por un valor aproximado de 1.500 millones de euros, setenta veces más que en 1999.

${ }^{44}$ COM (2012), p.16 
No obstante el interés y la relevancia de los documentos citados, es preciso indicar que se trata de documentos no vinculantes ${ }^{45}$, y que es el marco normativo de las Directivas de contratación el que realmente define el nuevo escenario vinculado al Comercio Justo.

\section{Las Directivas 2004/17/CE y 2004/18/CE sobre contratación pública}

Si bien la Comisión Europea, ya en su Comunicación de $1989 »$ Aspectos regionales y sociales de la contratación pública» había constatado que la contratación pública constituía un importante instrumento de política económica en atención a su importante volumen de gasto ${ }^{46}$, y el TJCE había consagrado la posibilidad de alcanzar objetivos sociales con la adjudicación de contratos públicos ${ }^{47}$, sin embargo, fueron las Directivas de tercera generación $\left(2004 / 17 / \mathrm{CE}^{48} \text { y } 2004 / 18 / \mathrm{CE}\right)^{49}$, las que permitieron considerar aspectos sociales en la contratación pública; concretamente, la Directiva europea 2004/18/CE, que regulaba los contratos públicos de obras, suministros y servicios, permitía la inclusión de criterios sociales y ambientales en los pliegos de contratación, siempre que estuvieran vinculados al objeto del contrato, estuvieran expresamente mencionados, y respetaran las libertades

45 Vid. Además la Plataforma Europea contra la Pobreza y la Exclusión Social - uno de los siete ejes de la Estrategia Europa 2020 - o el Acta del Mercado Único de 2010, que abordan la Responsabilidad Social Corporativa. La Comunicación de la Comisión al Parlamento Europeo, al Consejo, al Comité Económico y Social Europeo y al Comité de las Regiones, «Estrategia renovada de la Unión Europea (Unión Europea) para 2011-2014 sobre la responsabilidad social de las empresas» Bruselas, 25.10.2011,COM(2011) 681 final; la Comunicación de la Comisión de mayo de 2014 «Reforzar el papel del sector privado para lograr un crecimiento sostenible e inclusivo en los países en desarrollo» (COM(2014) 263 final); el Plan de Acción sobre derechos humanos y democracia 2015-2019 de la UE .

46 COM (89) 400 final.

47 Sentencia Gebroeders Beentjes (Sentencia del TJCE de 20 de septiembre de 1988, Asunto C-31/87, Rec. pág. I-4635). Vid. sobre esta sentencia, Teresa Medina Arnaiz , «La contratación pública socialmente responsable a través de la jurisprudencia del Tribunal de Justicia de la Unión Europea», Revista española de derecho administrativo, n. ${ }^{\circ} 153$ (2012), 5. Jaime Rodriguez-Arana Muñoz, «El procedimiento de adjudicación de los contratos de obras públicas en el Derecho Comunitario (El caso Gebroeders Beentjes Bve/Estado de los Países Bajos de 20 de septiembre de 1988)», Noticias CEE , n. 65 (1990), 133-138. José Antonio Moreno Molina, Contratos públicos: Derecho comunitario y Derecho español, (Madrid, McGraw-Hill, 1996), 62 y 63.

48 Directiva 2004/17/CE del Parlamento Europeo y del Consejo, con fecha 31 de marzo de 2004, que coordina los procedimientos de contrataciones de las entidades que operan en los sectores del agua, la energía, los transportes y los servicios postales.

49 Directiva 2004/18/CE del Parlamento Europeo y del Consejo, con fecha 31 de marzo de 2004, relativa a la coordinación de procedimientos para la adjudicación de contratos de obras públicas, contratos de suministro público y contratos de servicios públicos. 
fundamentales de la legislación comunitaria: libertad de circulación de mercancías, libre establecimiento y libre prestación de servicios; así como los principios que se derivan de las mismas: igualdad de trato, no discriminación, reconocimiento mutuo, proporcionalidad y transparencia.

En relación con las especificaciones técnicas a incluir en los pliegos ${ }^{50}$, la Directiva de 2004/18/CE en su Considerando 29 aludía expresamente a la posibilidad de prescribir características medioambientales, tales como un método de producción dado, y/o los efectos medioambientales específicos de grupos de productos o servicios. Admitía especificaciones definidas por etiquetas ecológicas, si las exigencias de la etiqueta se desarrollan y adoptan basándose en una información científica mediante un proceso en el que puedan participar todas las partes implicadas, como son los organismos gubernamentales, consumidores, fabricantes, distribuidores y organizaciones medioambientales, y si la etiqueta es accesible y está a disposición de todas las partes interesadas. [...] Dichas especificaciones técnicas deben indicarse claramente, de modo que todos los licitadores sepan qué abarcan los requisitos establecidos por el poder adjudicador.

En relación con la introducción de cláusulas sociales en las condiciones de ejecución, la Directiva en su Considerando 33 establecía su compatibilidad con la Directiva siempre y cuando no fueran directa o indirectamente discriminatorias y fueran señaladas en el anuncio de licitación o en el pliego de condiciones ${ }^{51}$.

En cuanto a los criterios de adjudicación del contrato, se señalaba que debían de tratarse de criterios objetivos que garantizasen el respeto de los principios de transparencia, no discriminación e igualdad de trato. La Directiva establecía que se debían definir criterios económicos y cualitativos que en su conjunto permitieran determinar la oferta económicamente más ventajosa para el poder adjudicador. Ahora bien, la determinación de esos criterios debía depender del objeto del contrato, de modo que permitieran

${ }^{50}$ El apartado 1, letra b), del anexo VI de la Directiva 2004/18 define el concepto de «especificación técnica», cuando se trate de contratos públicos de suministro, como «aquella especificación que figure en un documento en el que se definen las características exigidas de un producto [...], como, por ejemplo, los niveles de calidad, los niveles de actuación sobre el medio ambiente [...].

51 Asimismo, establece que: En particular, pueden tener por objeto favorecer la formación profesional en el lugar de trabajo, el empleo de personas que tengan especiales dificultades de inserción, combatir el paro o proteger el medio ambiente. Como ejemplo se pueden citar, entre otras, las obligaciones - aplicables a la ejecución del contrato- de contratar a desempleados de larga duración o de organizar acciones de formación para los desempleados o los jóvenes, de respetar en lo sustancial las disposiciones de los convenios fundamentales de la Organización Internacional del Trabajo (OIT) en el supuesto de que éstos no se hubieran aplicado en el Derecho nacional, de contratar a un número de personas discapacitadas superior al que exige la legislación nacional. 
evaluar el nivel de rendimiento de cada oferta respecto del objeto del contrato tal como se define en las especificaciones técnicas.

En relación con la cuestión concreta de las posibilidades de compra de productos de Comercio Justo por parte de los poderes adjudicadores, el debate se ha centrado en cómo compatibilizar los principios que presiden la contratación pública con la exigencia de unas específicas etiquetas sociales en el momento de identificar las necesidades del órgano de contratación, los criterios de adjudicación o al diseñar las especificaciones técnicas del contrato.

La sentencia de 10 de mayo de 2012 «NordHolland», que enfrentó a la Comisión Europea contra el Reino de los Países Bajos» ${ }^{52}$ afirma por primera vez que los contratos públicos pueden valorar positivamente los productos de «origen comercial más justo». En la citada sentencia, en relación con la adjudicación de un contrato público de suministro y mantenimiento de máquinas expendedoras de café, el TJUE entiende que la consideración de determinadas políticas sociales y ambientales en los procesos de contratación pública no sólo es una opción posible sino que en algunos casos está más que justificada para dar coherencia y efectividad a la gestión y ejecución de los recursos públicos. El TJUE examina, principalmente, la compatibilidad de requerir el suministro de productos de Comercio Justo con los principios de transparencia, igualdad de trato y no discriminación, a fin de determinar si la exigencia de utilizar una etiqueta o certificación específica - la etiquetas MAX HAVELAAR $-{ }^{53}$ en la formulación de las especificaciones técnicas del contrato y entre los criterios de adjudicación, contraviene estos principios cardinales en la contratación pública. La etiqueta se basa en cuatro criterios, a saber, que el precio pagado debe cubrir todos los gastos y comprender una prima adicional con respecto a los precios del mercado, que la producción debe ser objeto de una prefinanciación y que el importador debe mantener relaciones comerciales de larga duración con los productores. El Tribunal entiende que, para garantizar una concurrencia realmente efectiva, las referencias que en un anuncio de licitación aluden a las características, a la función de los productos o al proceso de producción de los mismos no pueden recaer en una etiqueta concreta cuando no se indi-

52 C-368/10. Comisión Europea contra Reino de los Países Bajos.

${ }^{53}$ La etiqueta MAX HAVELAAR es una etiqueta privada gestionada por una fundación de Derecho civil neerlandesa, con arreglo a las normas adoptadas por una organización internacional de referencia, la Fairtraide Labelling Organisation (FLO). Se utiliza en varios países, entre ellos los Países Bajos, con el fin de favorecer la comercialización de los productos procedentes del Comercio Justo. Esta etiqueta certifica que los productos a los que se concede se compran a organizaciones constituidas por pequeños productores de países en desarrollo a un precio y condiciones justos. 
can los criterios en que se basa, ni se autoriza a presentar «a través de cualquier medio adecuado la prueba de que un producto reunía esos criterios» (apartado nonagésimo séptimo).

A este respecto, señala que, tanto el principio de igualdad de trato como la obligación de transparencia derivada de éste, exigen que el objeto y los criterios de adjudicación de los contratos públicos estén claramente definidos y que se formulen en condiciones de competencia efectiva. Esto implica que la comparación y la evaluación de las ofertas se deben llevar a cabo de manera objetiva y en condiciones de igualdad para todos los licitadores, lo cual no resulta compatible con la exigencia de que los ingredientes que se suministraran estuvieran provistos únicamente de la etiqueta de Comercio Justo «Max Havelaar» 2, aunque se hiciera acompañar de la mención «o equivalente» ${ }^{54}$.

En definitiva, cabe sostener que en esta tercera generación de Directivas de contratación pública, según la interpretación del TJUE, nada se opone, en principio, a que como criterio de adjudicación del contrato se establezca el hecho de que un producto proceda del Comercio Justo, siempre que se indiquen los criterios en que se basan las etiquetas solicitadas o se autorice a presentar a través de cualquier medio adecuado la prueba de que un producto reunía esos criterios.

\section{La Directiva 2014/24/UE sobre contratación pública y el Comercio Justo}

La cuarta generación de directivas se enmarca en la Estrategia Europa $2020^{55}$, e introduce un cambio de paradigma en la medida en que configura a la contratación pública como medio idóneo para el fomento de políticas de integración social, ambiental y de innovación.

${ }^{54}$ Entiende el TJUE que al establecer en el pliego de condiciones que el hecho de que algunos productos que debían suministrarse estuvieran provistos de determinadas etiquetas daría lugar a la concesión de un determinado número de puntos en el marco de la selección de la oferta económicamente más ventajosa, sin haber indicado los criterios en que se basan esas etiquetas ni autorizado que se presentara a través de cualquier medio adecuado la prueba de que un producto reúne esos criterios, la provincia de Holanda Septentrional formuló un criterio de adjudicación incompatible con el artículo 53, apartado 1, letra a), de la Directiva 2004/18

55 Vid. José María Gimeno Feliú, El nuevo paquete legislativo comunitario sobre contratación pública. De la burocracia a la estrategia. (El contrato público como herramienta de liderazgo institucional de los poderes públicos). Cizur Menor, Aranzadi, 2014. Martín María Razquin Lizarraga, «Las nuevas Directivas sobre contratación pública de 2014: aspectos clave y propuestas para su transformación en España», Revista de Administración Pública, 196, 97-113. 
La nueva regulación, siguiendo los principios en los que se basó la sentencia «NordHolland», establece que las administraciones públicas pueden priorizar los aspectos sociales y medioambientales en sus respectivas licitaciones. La Directiva 2014/24/UE hace una referencia explícita al Comercio Justo al señalar que los poderes adjudicadores pueden adoptar criterios de adjudicación o las condiciones de ejecución de un contrato que se refieran al suministro o a la utilización de productos basados en un comercio equitativo durante la ejecución del contrato que vaya a ser adjudicado. Se indica que los criterios y condiciones relativos al comercio y sus condiciones pueden referirse, por ejemplo, al hecho de que el producto de que se trate proceda del Comercio Justo, incluyendo el requisito de pagar un precio mínimo y una prima a los productores» (párrafo 97$)^{56}$.

La introducción de cláusulas de Comercio Justo se presenta como una posibilidad, puesto que tal y como se indica en la propia Directiva 2014/24 «no sería apropiado imponer a la contratación unos requisitos medioambientales, sociales y de innovación de carácter general y obligatorio» ${ }^{57}$ y se dispone la necesidad de compatibilizar dichos objetivos con los principios que presiden la contratación pública.

Según reiterada jurisprudencia, el poder adjudicador está obligado a velar, en cada fase de un procedimiento de licitación, por el respeto del principio de igualdad de trato y, en consecuencia, por la igualdad de oportunidades entre todos los licitadores ${ }^{58}$. Una vez cumplidos estos requisitos de trato igualitario y no discriminatorio, los poderes adjudicadores pueden adquirir bienes de Comercio Justo.

La Directiva 2014/24 concreta en su Considerando 92 la condición esencial de todo criterio de adjudicación, y establece que: «Al evaluar la mejor relación calidad-precio, los poderes adjudicadores deberían determinar los criterios económicos y de calidad relacionados con el objeto del contrato que utilizarán a tal efecto. Estos criterios deben, pues, permitir efectuar una evaluación comparativa del nivel de rendimiento de cada oferta respecto del objeto del contrato tal como se define en las especificaciones técnicas. En el contexto de la mejor relación calidad-precio, la pre-

56 También se hace referencia al comercio equitativo en el parágrafo 64 de la Directiva 2014/23/UE de 26 de febrero de 2014, relativa a la adjudicación de contratos de concesión; y en el parágrafo 102 de la Directiva 2014/25/UE («sectores especiales»).

57 Considerando nonagésimo quinto de la Directiva 2014/24/UE y centésimo de la Directiva 2014/25/UE («sectores especiales»).

58 Vid. la sentencia de 13 de diciembre de 2016, European Dynamics Luxembourg y Evropaïi Dynamiki/Comisión, T-764/14, EU:T:2016:723, apartado 256 y jurisprudencia citada). 
sente Directiva incluye una lista no exhaustiva de posibles criterios de adjudicación que incluyen aspectos sociales y medioambientales.

El art. 67 de la Directiva establece que los criterios de adjudicación podrán incluir, entre otros factores, características sociales, medioambientales e innovadoras; o la comercialización del producto y sus condiciones.

Los poderes adjudicadores deberían determinar los criterios económicos y de calidad relacionados con el objeto del contrato que utilizarán a tal efecto; es decir se sigue manteniendo la exigencia de relación entre los criterios de adjudicación y el objeto del contrato. Sin embargo, a diferencia de las anteriores Directivas de contratación es preciso indicar que el art. 67.3 de la Directiva acoge una interpretación mucho más amplia del objeto del contrato. Así, se considerará que los criterios de adjudicación están vinculados al objeto cuando se refieran a las obras, suministros o servicios que deban facilitarse en virtud del contrato «en cualquiera de sus aspectos, y en cualquier etapa de su ciclo de vida», lo que incluye el proceso de producción, prestación o comercialización o cualquier otro proceso específico, «incluso cuando dichos factores no formen parte de su sustancia material ${ }^{59}$ ».

La Directiva 2014/24 integra el objeto del contrato en sentido amplio, comprensivo de los factores que intervienen en cualquier fase del ciclo de vida de la prestación; pero ello no altera la vinculación del criterio de adjudicación con el objeto del contrato, aunque sea a través de algunos de los factores que interviene en la realización de la concreta prestación a contratar.

\section{Las etiquetas de Comercio Justo}

En virtud de la Directiva 2014/24, los órganos de contratación que deseen adquirir obras, suministros o servicios con determinadas características medioambientales, sociales o de otro tipo pueden remitirse a etiquetas concretas $^{60}$, siempre que las exigencias de la etiqueta estén vinculadas al objeto del contrato. En consecuencia, el primer requisito de las etiquetas es que tienen que estar vinculadas al objeto del contrato.

59 Por ciclo de vida, según el artículo 2.20, se entienden «todas las fases consecutivas o interrelacionadas, incluidos la investigación y el desarrollo que hayan de llevarse a cabo, la producción, la comercialización y sus condiciones, el transporte, la utilización y el mantenimiento, a lo largo de la existencia de un producto, una obra o la prestación de un servicio, desde la adquisición de materias primas a la generación de recursos hasta la eliminación, el desmantelamiento y el fin de un servicio o de una utilización».

${ }^{60}$ La Directiva 2014/24/UE hace expresa referencia a la etiqueta ecológica europea, etiquetas ecológicas (pluri)nacionales o cualquier otra) (Considerando 75). 
En segundo lugar, se requiere que las exigencias de la etiqueta se adopten con arreglo a criterios objetivamente verificables, utilizando un procedimiento en el que los interesados, como los organismos gubernamentales, los consumidores, los fabricantes, los distribuidores y las organizaciones medioambientales, puedan participar; que los requisitos aplicables a efectos de la etiqueta hayan sido fijados por un tercero, y que todas las partes interesadas puedan acceder a la etiqueta y disponer de ella.

En definitiva, no se admite cualquier tipo de etiqueta, sino sólo aquellas que «sean accesibles a todas las partes interesadas», y que sean compatibles con las exigencias en materia de igualdad de acceso, no discriminación y transparencia. No se permite prescripciones de carácter técnico que limiten el objeto de la contratación a un determinado producto o marca sin mención de la expresión «o equivalente». Se deben aceptar todas aquellas otras etiquetas que confirmen que el producto cumple con los requisitos equivalentes. La carga en demostrar la equivalencia de características con respecto a la etiqueta exigida recae en el licitador ${ }^{61}$.

En ocasiones, se ha vislumbrado cierta desconfianza a admitir etiquetas en la contratación pública debido a que en determinados sectores existe cierta confusión entre los distintos sistemas de verificación y evaluación de los objetivos sociales que cada entidad se propone cumplir.

Las etiquetas de certificación de Comercio Justo se encuentran comprendidas en la categoría de «etiquetas sociales». La Comisión Europea ha definido las etiquetas sociales como las «palabras y símbolos sobre un producto con las que se intenta influir en las decisiones de compra de los consumidores garantizando el impacto social y ético de una operación empresarial en otras partes interesadas» ${ }^{62}$.

En el ámbito de la Unión Europea, los productos de Comercio Justo deben estar producidos y comercializados de acuerdo con la descripción establecida en la Resolución del Parlamento Europeo sobre Comercio Justo y Desarrollo de 6 de julio de 2006, cuyos principios se han indicado supra.

El sistema de certificación de Comercio Justo se lleva a cabo por dos vías distintas: la que se centra en el producto a través del sello «Fairtrade». La incorporación de este sello a un concreto producto garantiza que éste es conforme a las especificaciones sociales, económicas y medioambientales fijadas por la Organización Internacional de Etiquetado Justo (FLO) para su categoría de productos. Este sello tiene la mayor implantación a nivel mundial.

61 Considerando 74 de la Directiva 2014/24/UE.

${ }^{62}$ Libro Verde Fomentar un marco europeo para la responsabilidad social de las empresas, COM (2001) 366 final, de 18 de julio de 2001. 
La segunda vía de certificación se centra en la cadena de suministro, y verifica que los productos son importados y/o distribuidos por organizaciones de Comercio Justo; éstas organizaciones están acreditadas como tales por el sistema de certificación de la red mundial de Organizaciones de Comercio Justo (WFTO) ${ }^{63}$. En consecuencia, el logotipo WFTO no es una marca de producto, sino que se aplica a organizaciones de Comercio Justo e indica que una concreta organización ha respetado los diez principios de comercio justo en la elaboración y comercialización de sus productos.

Cualquier otra organización, sello o etiqueta acreditada conforme a los diez principios de la Resolución del Parlamento Europeo sobre Comercio Justo y Desarrollo o la Certificación ISO 17065 (FLOCERT) se considera «certificación equivalente».

\section{La incorporación de cláusulas de Comercio Justo en en Ley 9/2017, de 8 de noviembre, de Contratos del Sector Público}

\section{Introducción}

El Texto Refundido de la Ley de Contratos del Sector Público de 2011 ya admitía la posibilidad de introducir criterios de Comercio Justo como criterio de desempate, es decir, siempre que las proposiciones igualasen en sus términos a las más ventajosas desde el punto de vista de los criterios que sirvieran de base para la adjudicación ${ }^{64}$.

La Ley 9/2017, de 8 de noviembre, de Contratos del Sector Público (en lo sucesivo LCSP), ya no habla de la inclusión voluntaria de los criterios sociales o medioambientales. En su exposición de motivos señala que «por primera vez, y para lograr el objetivo de conseguir una mejor relación calidad-precio, se establece la obligación de los órganos de contratación de velar porque el diseño de los criterios de adjudicación permita obtener obras,

63 También se consideran sellos de Comercio Justo equivalentes, entre otros: Naturland Fair, EcoCert Fair Trade, Fair for Life y Símbolo por Pequeños Productores.

${ }^{64}$ Disposición Adicional Cuarta, apdo 5. del Real Decreto Legislativo 3/2011, de 14 de noviembre, por el que se aprueba el texto refundido de la Ley de Contratos del Sector Público. Vid. sobre cláusulas sociales en la Ley 30/2007, de contratos del Sector público, Miguel Angel Bernal Blay, «Hacia una contratación pública socialmente responsable: las oportunidades de la ley 30/2007, de 30 de octubre, de contratos del sector público», Revista Aragonesa de Administración Pública, n. 10, (Zaragoza, Instituto Aragonés de Administración Pública, 2008). En relación a la Ley de contratos 3/2011, José Pernas García (dir) Contratación pública estratégica, (Cizur Menor Editorial Aranzadi, 2014). Sobre comercio justo, Ana Belén Casares Marco, «Comercio justo y fomento de la contratación pública Socialmente Responsable (1)» Revista de la contratación administrativa y de los contratistas, n 123, 2013, Editorial Wolters Kluwer, 68-83. 
suministros y servicios de gran calidad, concretamente mediante la inclusión de aspectos cualitativos, medioambientales, sociales e innovadores vinculados al objeto del contrato» ${ }^{65}$.

La LCSP en su Exposición de Motivos hace, además, una primera alusión a los principios de Comercio Justo al establecer que ... «con el ánimo de favorecer el respeto hacia los derechos humanos, y en especial hacia los derechos laborales básicos de las personas trabajadoras y de los pequeños productores de países en vías de desarrollo, se introduce la posibilidad de que tanto los criterios de adjudicación como las condiciones especiales de ejecución incorporen aspectos sociales del proceso de producción y comercialización referidos a las obras, suministros o servicios que hayan de facilitarse con arreglo al contrato de que se trate, y en especial podrá exigirse que dicho proceso cumpla los principios de Comercio Justo que establece la Resolución del Parlamento Europeo sobre Comercio Justo y desarrollo (2005/2245(INI)) en su apartado $2 »$.

La responsabilidad de respetar los derechos humanos exige a los Estados y, en general a todas las autoridades públicas, el impulso y fomento de prácticas de Comercio Justo en las adjudicaciones de contratos públicos ${ }^{66}$.

En definitiva, la incorporación de cláusulas sociales no es una cuestión discrecional para los órganos de contratación. Los poderes adjudicadores están obligados a incorporar aspectos sociales en la contratación. Así el art. 1.3 LCSP, señala que en toda contratación pública se incorporarán de manera transversal y preceptiva criterios sociales y medioambientales siempre que guarde relación con el objeto del contrato, en la convicción de que su inclusión proporciona una mejor relación calidad-precio en la prestación contractual, así como una mayor y mejor eficiencia en la utilización de los fondos públicos.

El legislador entiende que la incorporación de criterios sociales y medioambientales mejora la relación calidad-precio, y supone un mejor gasto del dinero público; el principio de libre competencia debe cohonestarse con el principio de solidaridad y debe ser modulado por el principio de proporcionalidad ${ }^{67}$.

65 Vid. José Antonio Moreno Molina, Una nueva contratación pública social, ambiental, eficiente, transparente y electrónica (Albacete, Editorial Bomarzo, 2018). Aritz Romeo Ruiz, «Las cláusulas sociales en la Ley 9/2017, de 8 de noviembre, de Contratos del sector público», Revista española de Derecho Administrativo, 2018, n 191, 2018, 297-325.

${ }^{66} \mathrm{Vid}$. en este sentido el Real Decreto 94/2018, de 2 de marzo, por el que se crea la Comisión Interministerial para la incorporación de criterios sociales en la contratación pública, que alude expresamente al Comerio Justo.

67 Vid en este sentido, Jaime Pintos Santiago, Los principios generales de desarrollo humano y sostenibilidad ambiental en la contratación pública, (Madrid, Instituto Nacional de Administración Pública, 2017), 16. 
La incorporación de cláusulas de Comercio Justo deberá determinarse en cada caso concreto en función del objeto del contrato y de las políticas públicas relacionadas con el mismo que pretendan implementarse. La LCSP contempla varias posibilidades para que los órganos de contratación incorporen aspectos de Comercio Justo en sus compras públicas: 1. En la fase de preparación del contrato, al establecer las especificaciones técnicas y en la regulación de las Etiquetas; 2. Al establecer los criterios de adjudicación del contrato; 3 . Al establecer condiciones especiales de ejecución del contrato ${ }^{68}$.

\section{Fase de preparación de los contratos}

El art. 28 LCSP obliga a justificar la naturaleza y extensión de las necesidades que pretenden cubrirse mediante el contrato proyectado, así como la idoneidad de su objeto y contenido para satisfacerlas; señala, asimismo, que las entidades del sector público valorarán la incorporación de consideraciones sociales, medioambientales y de innovación como aspectos positivos en los procedimientos de contratación pública.

La primera cuestión que se plantea es si cabe definir el objeto incorporando al título del contrato la dimensión social de la adquisición. Así, por ejemplo, puede plantearse la posibilidad de contratos de suministros y servicios cuyo objeto sea el «Servicio de catering de Comercio Justo». La respuesta es afirmativa. Así, desde la fase de preparación del contrato, el órgano contratante deberá tener en cuenta la existencia de posibles compromisos adquiridos por parte de la entidad pública con relación al consumo de productos de Comercio Justo. En este caso, deberán incorporarse productos de Comercio Justo, siempre que las características del contrato lo permitan. En esta fase, los poderes adjudicadores gozan de libertad para determinar el objeto del contrato que promueva el Comercio Justo.

La LCSP no prevé la posibilidad de incorporar criterios sociales en la solvencia técnica para la contratación de suministros. No obstante, en la medida en que dichos criterios estén incluidos en la definición del objeto del contrato, cabe derivar la necesidad de que los licitadores garanticen su capacidad para suministrar productos de Comercio Justo ${ }^{69}$.

${ }^{68}$ Vid, sobre medidas la inserción de medidas para la promoción del respeto a los derecho humanos, Joaquín Tornos, Agustí Fernández de Losada, Anna Calvete, Juan Ambrós. Tornos Abogados. Guía para la protección y promoción de los derechos humanos en la contratación pública, Barcelona, 2017. Acceso, el 11 de octubre de 2019, https://nexescat.org/ PDF/Guia-protecion-y-promocion-DDHH-ESP.pdf.

${ }^{69}$ En cualquier caso, el órgano contratante, además de los medios establecidos por el art. 89 LCSP para acreditar la solvencia del licitador, deberá aceptar cualquier otro medio de prueba ade- 
Una vez que la entidad adjudicadora ha definido el objeto del contrato, debe traducirlo en especificaciones técnicas detalladas que puedan aplicarse directamente a un procedimiento de contratación pública. Las especificaciones técnicas constituyen criterios de ineludible cumplimiento; si la oferta del licitador no cumple con las especificaciones técnicas, no podrá ser admitida. Las especificaciones técnicas deben estar vinculadas al objeto del contrato.

En principio, no pueden admitirse especificaciones técnicas que obliguen a emplear productos de fabricación o elementos determinados. Ahora bien, si no cabe la posibilidad de definir el objeto del contrato a través de especificaciones suficientemente precisas, se debe admitir indicaciones técnicas, siempre que se acompañe de las palabras o equivalente. Debe garantizar a los licitadores acceso en condiciones de igualdad al procedimiento de contratación.

Así, cuando en las prescripciones técnicas se haga referencia a una etiqueta o sello de Comercio Justo, debe admitirse cualquier oferta que demuestre cumplir con los estándares predefinidos por dicha etiqueta; por lo tanto es necesario y exigible introducir la expresión «y equivalente ${ }^{70} 》$.

Las etiquetas de Comercio Justo constituyen medio de prueba de que las obras, los servicios o los suministros cumplen las características exigidas de Comercio Justo y tienen que cumplir una serie de condiciones a las que ya nos hemos referido al tratar la Directiva 2014/24/UE.

Es preciso insistir en que los poderes adjudicadores deberán aceptar todas las etiquetas u otros medios de prueba que verifiquen que las obras, suministros o servicios cumplen requisitos que sean equivalentes a aquellos que son exigidos para la obtención del sello o etiqueta de Comercio Justo.

\section{Los criterios de adjudicación de los contratos}

Otra de las fases en las que cabe valorar los aspectos vinculados al Comercio Justo es a la hora de establecer los criterios de adjudicación de los contratos $^{71}$. Es preciso destacar que la nueva legislación de contratos sustituye el criterio de adjudicación hasta ahora vigente de «oferta económica-

cuado de la solvencia técnica del licitador, como pudiera ser un informe emitido por un organismo técnico oficialmente reconocido, en los términos previstos en el artículo 128.1 LCSP.

70 Vid. en este sentido, la STJUE de 25 de octubre de 2018, Roche Lietuva, C-413/17. Vid asimismo, en relación con las etiquetas, José Pernás García, «El uso de las etiquetas para la integración de consideraciones ambientales y sociales en los procedimientos de adjudicación de contratos públicos» en Revista de Contratación Administrativa Práctica, n. ${ }^{\circ}$ 125, 2013.

71 Vid. Silvia Díez Sastre, «Las cláusulas sociales en la contratación pública», Anuario de la Facultad de Derecho de la Universidad Autónoma de Madrid, n 21 (2017), 195-115. Isabel Gallego Córcoles, «Las cláusulas sociales como criterio de adjudicación», Contratación Administrativa Práctica, n 152, 2017, 84-95. 
mente más ventajosa» por el criterio de la mejor relación calidad-precio. El art. 145 LCSP establece que la adjudicación de los contratos se realizará utilizando una pluralidad de criterios de adjudicación con base en la mejor relación calidad-precio. La mejor relación calidad-precio se evaluará con arreglo a criterios económicos y cualitativos.

Los órganos de contratación deben detallar y publicar los criterios para la adjudicación del contrato y la ponderación relativa que se asigna a cada uno de los criterios para que los licitadores estén al tanto de ellos a la hora de preparar sus ofertas.

Teniendo en cuenta que la mejor relación calidad-precio se determinará sobre la base de varios subcriterios diferentes, la entidad adjudicadora puede ponderar el criterio del Comercio Justo. Los criterios de adjudicación nunca pueden atribuir una libertad de elección absoluta a los poderes adjudicadores. Deben establecerse criterios específicos, vinculados al objeto del contrato y cuantificables.

La necesaria vinculación de los aspectos sociales con el objeto del contrato debe entenderse ahora en un sentido amplio, según el apartado 6 del artículo $145^{72}$

A diferencia de las especificaciones técnicas, los criterios de adjudicación pueden establecer la posibilidad de otorgar mayor puntuación a cualquier producto o servicio que incorpore en su prestación productos de Comercio Justo, cuyo rendimiento sea mejor al del nivel mínimo exigido.

Serán los pliegos de cláusulas administrativas particulares los que incorporarán los criterios de adjudicación con arreglo a la mejor relación calidad-precio y donde vendrán valorados aspectos sociales, medioambientales y relativos a otras políticas públicas vinculados al objeto del contrato.

Además la LCSP establece la posibilidad de introducir mejoras como criterio de adjudicación, siempre que estén suficientemente especificadas $^{73}$, así como criterios de adjudicación específicos para el desempate en

72 El precepto dispone que:

Se considerará que un criterio de adjudicación está vinculado al objeto del contrato cuando se refiera o integre las prestaciones que deban realizarse en virtud de dicho contrato, en cualquiera de sus aspectos y en cualquier etapa de su ciclo de vida, incluidos los factores que intervienen en los siguientes procesos:

a) en el proceso específico de producción, prestación o comercialización de, en su caso, las obras, los suministros o los servicios, con especial referencia a formas de producción, prestación o comercialización medioambiental y socialmente sostenibles y justas;

b) o en el proceso específico de otra etapa de su ciclo de vida, incluso cuando dichos factores no formen parte de su sustancia material.

${ }^{73} \mathrm{El}$ art. 145.7 considera que se cumple esta exigencia cuando se fijen, de manera ponderada, con concreción: los requisitos, límites, modalidades y características de las mismas, así como su necesaria vinculación con el objeto del contrato. 
los casos en que, tras la aplicación de los criterios de adjudicación, se produzca un empate entre dos o más ofertas ${ }^{74}$. Dichos criterios de adjudicación para el desempate deberán estar vinculados al objeto del contrato y según el art. 147 LCSP pueden referirse, entre otros aspectos, a las ofertas de entidades reconocidas como Organizaciones de Comercio Justo para la adjudicación de los contratos que tengan como objeto productos en los que exista alternativa de Comercio Justo.

El incumplimiento de los compromisos contenidos en la proposición de la licitadora relativos a los criterios de adjudicación de carácter social o medioambiental, o relativos a las mejoras o variantes, supondrán la resolución del contrato cuando dichos compromisos tengan carácter esencial, conforme a lo dispuesto en el artículo $211 \mathrm{f}$ ) de la LCSP, o pueden dar lugar a la imposición de penalidades ${ }^{75}$.

\section{Condiciones especiales de ejecución de los contratos}

El art. 201 de la LCSP dispone que los órganos de contratación tomarán las medidas pertinentes para garantizar que en la ejecución de los contratos los contratistas cumplen las obligaciones aplicables en materia medioambiental, social o laboral ${ }^{76}$.

Las condiciones de ejecución del contrato tienen por objeto establecer requisitos específicos en relación con la ejecución, de modo que no inciden en la evaluación de las ofertas ${ }^{77}$.

El órgano contratante puede establecer condiciones adicionales del contrato, independientes de las especificaciones técnicas y de los criterios de adjudicación ${ }^{78}$. Estas condiciones se relacionan únicamente con el cumplimiento del contrato, tras la adjudicación del contrato a la mejor oferta calidad-precio. En este sentido, el art. 202 LCSP exige la vinculación al objeto

74 art. 147 LCSP.

75 Previstas en el artículo 192. Las cuantías de cada una de ellas no pueden ser superiores al $10 \%$ del precio del contrato, IVA, excluido, ni el total de las mismas pueda superar el 50 por cien del precio del contrato.

${ }^{76}$ Se trata de las medidas establecidas en el derecho de la Unión Europea, el derecho nacional, los convenios colectivos o por las disposiciones de derecho internacional medioambiental, social y laboral que vinculen al Estado y en particular las establecidas en el anexo V

77 Vid. En este sentido, el Considerando (104) de la Diretiva 2014/24/UE «El propósito de las condiciones de ejecución de un contrato es establecer requisitos específicos en relación con dicha ejecución. De modo diferente a como ocurre con los criterios para la adjudicación de contratos, que constituyen la base para hacer una evaluación comparativa de la calidad de las ofertas, las condiciones de ejecución de un contrato constituyen requisitos objetivos fijos que no inciden en la evaluación de las ofertas».

78 Caso Beentjes, sentencia del TJUE en el caso 31/87. 
del contrato, que las condiciones no sean directa o indirectamente discriminatorias, sean compatibles con el derecho de la UE y se indiquen en el anuncio de licitación y en los pliegos.

Dentro de las consideraciones de tipo social o relativas al empleo que pueden introducirse como condiciones especiales de adjudicación, el art. 202 LCSP en su número 2, hace referencia a «aquellas consideraciones que busquen favorecer a los pequeños productores de países en desarrollo, con los que se mantienen relaciones comerciales que les son favorables tales como el pago de un precio mínimo y una prima a los productores o una mayor transparencia y trazabilidad de toda la cadena comercial».

De la lectura de dicha disposición, cabe postular que las entidades adjudicadoras pueden incluir en las cláusulas de cumplimiento del contrato aspectos de compra pública de Comercio Justo, imponiéndole al adjudicatario en los pliegos como condiciones especiales de ejecución.

Esto será posible, evidentemente, en aquellos contratos susceptibles de incorporar en su prestación productos de Comercio Justo y siempre que el órgano de contratación determine expresamente esta posibilidad. Esta condición deberá incorporarse en el pliego de cláusulas administrativas particulares como condición especial de ejecución, de modo que la empresa adjudicataria se verá obligada a incorporarlas en la prestación del servicio o en el contenido del suministro.

Además, es preciso destacar que la propia legislación de contratos (art. 202) exige el establecimiento en el pliego de cláusulas administrativas particulares de al menos una de las condiciones especiales de ejecución de entre las que enumera en el apartado segundo. Son numerosas las consideraciones de tipo social y medioambiental que se recogen en el precepto.

El Pliego podrá contener las penalidades asociadas al incumplimiento de las condiciones especiales del contrato ${ }^{79} \mathrm{o}$ atribuir a las condiciones especiales recogidas en el pliego el carácter de obligación esencial, de modo que su incumplimiento derivaría en una causa de resolución del contrato ${ }^{80}$.

\section{Conclusiones}

La contratación pública debe contribuir al desarrollo de un comercio equitativo. La inserción de aspectos de política social y medioambiental en

${ }^{79}$ Las penalidades deberán ser proporcionales a la gravedad del incumplimiento y las cuantías de cada una de ellas no podrán ser superiores al 10 por ciento del precio del contrato, IVA excluido, ni el total de las mismas superar el 50 por cien del precio del contrato.

80 Vid. el artículo 211.f) LCSP. 
los procesos de licitación pública, se ha constituido en una exigencia ineludible para los órganos de contratación en el sector público.

La legislación de contratos del sector público establece que en toda contratación pública se deben introducir de manera transversal criterios sociales y medioambientales que guarden relación con el objeto del contrato. Ahora bien, el legislador, salvo excepciones, no establece cuáles son los criterios sociales y medioambientales que obligatoriamente han de incardinarse en cada fase del proceso de contratación, ni se establece el nivel de exigencia de dichas cláusulas.

Desde esa perspectiva cabe sostener que el alcance de la contratación pública como instrumento para el cumplimiento de un Comercio Justo dependerá del compromiso adquirido por cada órgano de contratación a la hora de incorporar este objetivo a las adquisiciones públicas. Es fundamental que las distintas administraciones y órganos de contratación establezcan estrategias claras para delimitar de forma clara los aspectos a integrar en las distintas fases del procedimiento de contratación.

Tal y como hemos visto, el debate sobre las posibilidades de compra de productos de Comercio Justo por parte de los poderes adjudicadores se ha centrado en compatibilizar los principios que presiden la contratación pública con la exigencia de un determinado método de producción o de unas específicas etiquetas sociales en el momento de identificar las necesidades del órgano de contratación o al diseñar las especificaciones técnicas del contrato.

La nueva legislación de contratos da un paso adelante y permite que los criterios de Comercio Justo se incluyan en el objeto mismo del contrato, en las especificaciones técnicas que deben satisfacer los contratistas seleccionados, en los criterios de adjudicación del contrato y/o en las condiciones de ejecución del contrato. Ahora bien, como hemos visto, no cabe exigir que los productos lleven una etiqueta/certificación específica de Comercio Justo. La contratación pública no cabe ser utilizada para falsear, ni restringir la competencia.

En definitiva, los objetivos de la compra pública estratégica obligan a replantearse el propio concepto de competencia y darle un nuevo enfoque. Tal y como se ha señalado en el Informe de febrero de 2019 «Derecho de la Competencia de la UE y Sostenibilidad en los Sistemas Alimentarios: los enlaces $\operatorname{rotos}^{81}{ }_{1}$ debemos plantearnos cuál es el precio aceptable para evitar la explotación en las cadenas de suministro o si

${ }^{81}$ Los autores del informe, el Dr. Tomaso Ferrando (de la Facultad de Derecho de la Universidad de Bristol) y el Dr. Claudio Lombardi (de la Universidad de KIMEP). Vid. http:// comerciojusto.org/wp-content/uploads/2019/09/REPORT_-Addressing-the-Broken-LinksFTAO.pdf 
una determinada cadena de suministro será alguna vez sostenible si no es justa con los pequeños productores y trabajadores que cultivan nuestros alimentos.

Como se sostiene en la Guía para considerar aspectos sociales aprobado por la Comisión europea, (...) los cambios de alto perfil, como cambiar a un café producido de manera sostenible o a través de un comercio ético en la cafetería, pueden ayudar a generar conciencia sobre la política y a vincularla con otros proyectos sociales ${ }^{82}$.

\section{Sobre la autora}

Carmen Agoués es Doctora en Derecho Administrativo y Profesora Titular de Derecho Administrativo de la Universidad del País Vasco desde 1989. Ha impartido docencia en la totalidad de las asignaturas vinculadas al Área de Derecho Administrativo, tanto en el Grado de Derecho, Grado de Empresariales como en el Grado de Criminología, así como en los diversos Postgrados, y tanto en la Facultad de Derecho como en la Facultad de Ciencias Empresariales de la Universidad del País Vasco. Asimismo, ha impartido durante muchos cursos la asignatura de Urbanismo y Ordenación del Territorio. Forma parte del cuadro de profesores permanentes de los Másteres de Acceso a la Abogacía y en el Máster de Integración Europea, ambas organizadas por la UPV. Ha participado en numerosos proyectos de investigación tanto a nivel estatal como en el ámbito europeo. Ha trabajado las siguientes Líneas de investigación: el urbanismo y la ordenación del territorio; el régimen jurídico de la educación; la potestad sancionadora; el régimen jurídico del subsuelo y el derecho de propiedad; los recursos judiciales contra las disposiciones generales de carácter administrativo; y los contratos del sector público. Es autora de tres monografías y de numerosas publicaciones en artículos científicos. Ha sido reconocida con cuatro sexenios de investigación por parte de la Comisión Nacional Evaluadora de la Actividad Investigadora (CNEAI).

82 Vid. el Catálogo de la Comisión Europea: «Adquisiciones sociales. Una guía para considerar aspectos sociales en la contratación pública. (La Europa social), 28/01/2011, pág. 17. Acceso, el 11 de octubre de 2019.http://www.conr.es/sites/default/files/archivos/Adquisiciones $\% 20$ sociales.\%20Una\%20guia\%20para\%20considerar $\% 20$ aspectos $\% 20$ sociales $\% 20$ en $\% 201$ as $\% 20$ contrataciones $\% 20$ publicas. $\% 20$ Comision\%20Europea..pdf 


\section{About the author}

Carmen Agoués is a PhD in Administrative Law and Full Professor of Administrative Law at the University of the Basque Country since 1989. Teaching in Administrative Law Area in the Law Degree, in the Business Degree and in the Criminology Degree, as well as in the various Postgraduate degrees, and both in the Faculty of Law and in the Faculty of Business Sciences of the University of the Basque Country. She has also been professor of Urban Planning and Spatial Planning. She is part of the permanent professors of the Master's Degree Programs for Access to the Legal Profession and the Master's Degree in European Union, both organized by the University of the Basque Country. He has participated in numerous research projects both at the state level and at the European level. She has worked on the following lines of research: urban planning and spatial planning; the legal regime of education; the sanctioning power; the social function of property right; judicial appeals against general administrative provisions; and public sector contracts. She is the author of three monographs and numerous publications in scientific articles. The National Commission has recognized her research with four six-year periods of research for Evaluating Research Activity. 


\section{Derechos de autor}

Los derechos de autor (para la distribución, comunicación pública, reproducción e inclusión en bases de datos de indexación y repositorios institucionales) de esta publicación (Cuadernos Europeos de Deusto, CED) pertenecen a la editorial Universidad de Deusto. El acceso al contenido digital de cualquier número de Cuadernos Europeos de Deusto es gratuito inmediatamente después de su publicación. Los trabajos podrán leerse, descargarse, copiar y difundir en cualquier medio sin fines comerciales y según lo previsto por la ley; sin la previa autorización de la Editorial (Universidad de Deusto) o el autor. Así mismo, los trabajos editados en CED pueden ser publicados con posterioridad en otros medios o revistas, siempre que el autor indique con claridad y en la primera nota a pie de página que el trabajo se publicó por primera vez en CED, con indicación del número, año, páginas y DOI (si procede). Cualquier otro uso de su contenido en cualquier medio o formato, ahora conocido o desarrollado en el futuro, requiere el permiso previo por escrito del titular de los derechos de autor.

\section{Copyright}

Copyright (for distribution, public communication, reproduction and inclusion in indexation databases and institutional repositories) of this publication (Cuadernos Europeos de Deusto, CED) belongs to the publisher University of Deusto. Access to the digital content of any Issue of Cuadernos Europeos de Deusto is free upon its publication. The content can be read, downloaded, copied, and distributed freely in any medium only for non-commercial purposes and in accordance with any applicable copyright legislation, without prior permission from the copyright holder (University of Deusto) or the author. Thus, the content of CED can be subsequently published in other media or journals, as long as the author clearly indicates in the first footnote that the work was published in CED for the first time, indicating the Issue number, year, pages, and DOI (if applicable). Any other use of its content in any medium or format, now known or developed in the future, requires prior written permission of the copyright holder. 